
made on 17 February 2015.

Research, part of a Special Feature on Pathways of Resilience in a Rapidly Changing Alaska

\title{
Applications of resilience theory in management of a moose-hunter system in Alaska
}

\author{
Casev L. Brown ${ }^{1,2}$, Kalin A. Seaton $^{3}, \underline{\text { Todd J. Brinkman }}^{1,2}$, Eugénie S. Euskirchen $^{2,4}$ and Knut Kielland $^{1,2}$
}

\begin{abstract}
We investigated wildfire-related effects on a slow ecological variable, i.e., forage production, and fast social-ecological variables, i.e., seasonal harvest rates, hunter access, and forage offtake, in a moose-hunter system in interior Alaska. In a 1994 burn, average forage production increased slightly (5\%) between 2007 and 2013; however, the proportional removal across all sites declined significantly $(10 \%)$. This suggests that moose are not utilizing the burn as much as they have in the past and that, as the burn has aged, the apparent habitat quality has declined. Areas with a greater proportion of accessible burned area supported both high numbers of hunters and harvested moose. Our results suggest that evaluating ecological variables in conjunction with social variables can provide managers with information to forecast management scenarios. We recommend that wildlife managers monitor fast variables frequently, e.g., annually, to adapt and keep their management responsive as resources fluctuate; whereas slower variables, which require less frequent monitoring, should be actively incorporated into long-term management strategies. Climate-driven increases in wildfire extent and severity and economically driven demographic changes are likely to increase both moose density and hunting pressure. However, the future resilience of this moose-hunter system will depend on integrated management of wildfire, hunter access, and harvest opportunities.
\end{abstract}

Key Words: Alaska; moose; resilience; slow and fast variables; wildlife management

\section{INTRODUCTION}

Sustainably managing wildlife species with diverse utilization values is one of the greatest challenges for contemporary wildlife management agencies. Management decisions can become especially difficult near communities that rely on available wildlife populations for ecosystem services such as hunting. In North America, managers often focus on one variable, e.g., abundance, to address decisions related to harvest. In doing so, other variables, e.g., seasonal wildlife distribution, fluctuating habitat conditions, and hunter participation, are typically ignored, despite their obvious relevance to sustainable management.

In Alaska, hunting remains an integral practice to state wildlife management. Alaska is unique compared to the continental United States in that many rural residents rely on the seasonal harvest of wild game to maintain food security (Loring and Gerlach 2009). Even in urban centers like Anchorage, many families consume wild-caught fish and game, even if they did not harvest these resources themselves (Titus et al. 2009). Alaska has not experienced the sharp declines in hunter activity observed in the continental United States (Leonard 2007, Schuett et al. 2009). However, Alaska is undergoing dramatic socioeconomic and cultural transitions. For example, rural residents of the state are increasingly moving to urban areas (Martin et al. 2008) so that areas that are accessible along the road system have become increasingly important to hunters throughout the state.

Just as human communities are undergoing transition, Alaska's boreal forests are experiencing rapid change as a result of climate warming. Alaska's boreal region has warmed twice as rapidly as the global average (Markon et al. 2012), affecting a host of processes including an increase in plant disease and insect outbreaks (Berg et al. 2006), thawing of permafrost (Jorgenson et al. 2010), earlier snowmelt and later freeze-up (Euskirchen et al. 2010), and increased wildfire frequency (Kasischke et al. 2010). Wildfire is the most common ecological disturbance in the boreal forest (Viereck 1973, Kasischke et al. 2002), and recent studies predict an increase in frequency, extent, and severity of fire in interior Alaska under a changing climate regime (Duffy et al. 2005). Wildfire affects habitat quality and subsequent utilization patterns of several boreal wildlife species (Nelson et al. 2008, Kofinas et al. 2010). The immediate impact following a fire is typically a reduction in wildlife numbers; however, as vegetation begins to regenerate, populations of some species can rebound and even increase (Nelson et al. 2008).

Moose (Alces alces) can benefit nutritionally from postfire regeneration of deciduous browse (Schwartz and Franzman 1989). Fires create and maintain spatially heterogenous moose habitats. In interior Alaska, moose are the primary terrestrial subsistence resource (Scott et al. 2001, Nelson et al. 2008), and moose hunting has been identified as an important cultural and recreational activity to hunters throughout the state (Brinkman et al. 2013). Prescribed burns have been identified as a management option in interior Alaska, but the lack of resources during fire prescription and limited public support have restricted the application of this habitat improvement effort (Boertje et al. 2009). Thus, natural postfire habitat characteristics can have important consequences for the social-ecological interactions among hunters, moose, and the environment, i.e., a moose-hunter system.

As Alaska's population continues to change, managers will likely see more tightly coupled interactions between moose and hunters along road systems. Concurrently, changing wildfire conditions attributable to climate warming can impact the dispersion of moose and hunters across the landscape. However, these interactions are poorly known. This is the first study that investigates wildfire-related effects on several social-ecological variables in a moose-hunter system in Alaska. This research should have broad appeal to wildlife managers in other regions because it offers a framework that includes monitoring slow and

${ }^{1}$ Biology and Wildlife Department, University of Alaska Fairbanks, ${ }^{2}$ Resilience and Adaptation Program, University of Alaska Fairbanks, ${ }^{3}$ Alaska Department of Fish and Game, Fairbanks, ${ }^{4}$ Institute of Arctic Biology, University of Alaska Fairbanks 
fast social-ecological variables over time to forecast changes to wildlife resources, and harvest of these resources, following a disturbance.

\section{METHODS}

The moose-hunter system consists of a set of social and ecological components that are affected by a disturbance, i.e., wildfire (Fig. 1). Social components in this system include proximity of wildfire to human travel corridors, hunter access, and hunter opportunity. The proximity of wildfire to travel corridors, i.e., roads and offroad vehicle trails, could facilitate access, or the ability of hunters to travel through burned areas. Hunter access into regenerating moose habitat will strongly influence hunter opportunities (Berman and Kofinas 2004) and may affect the overall harvest rate of entire units (Schmidt et al. 2005).

Fig. 1. Diagram of the social and ecological components in a moose-hunter system following a wildfire disturbance in interior Alaska. Arrows represent the interactions between components. Research in our system focused on a slow variable (oval with blue outline) and fast variables (ovals with red outline). Purple ovals represent exogenous variables that can also affect system components.

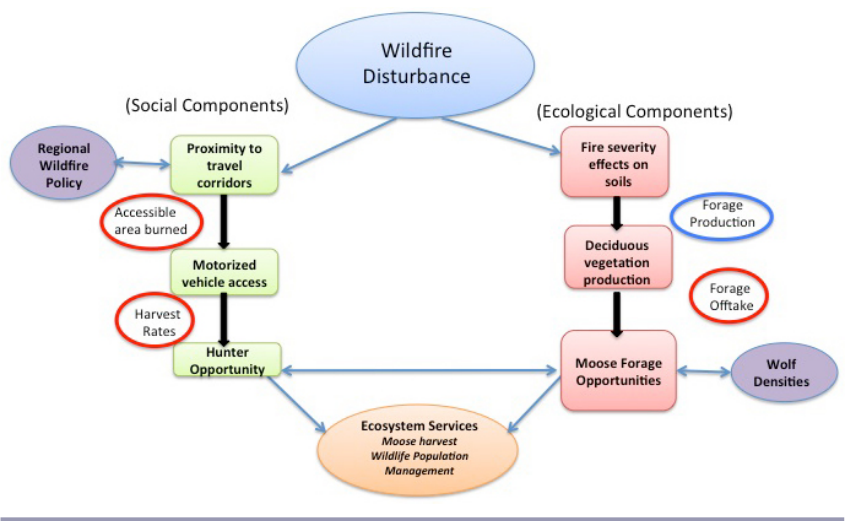

The ecological components in this system include fire-severity effects on soil properties, deciduous forage production, and moose densities (Fig. 1). Severe fires reduce the depth of the residual soil organic mat, facilitating the recruitment of deciduous seedlings (Johnstone and Kasischke 2005, Johnstone and Chapin 2006) that enhance the production of deciduous forage. This fire-severity effect on forest recovery can persist over several decades, converting stands from black spruce (Picea mariana) to aspen (Populus tremuloides; Shenoy et al. 2011). Moose selectively feed on deciduous plant species, e.g., willow (Salix spp.) and aspen, that are more likely to establish in high-severity sites (Lord 2008). Predators also play a significant role in moose systems, when moose population density is low (Gasaway et al. 1992), and their presence should also be considered when investigating the influence of fire on moose densities.

\section{Study area}

Our research took place in game management unit (GMU) 20, in interior Alaska, $40 \mathrm{~km}$ east of Delta Junction. GMU 20 is divided into 6 subunits (A, B, C, D, E, F) comprising $130,000 \mathrm{~km}^{2}$. We focused on GMU 20D located in the southeastern portion of GMU 20 (Fig. 2). GMU 20D supports some of the highest moose densities in the state, with correspondingly high levels of harvest, and has a history of large wildfires (DuBois 2010). Unit 20D has been subdivided into 4 areas for moose management purposes, and our research was located within 2 of these subunits: southwestern GMU 20D (SW20D), the area south of the Tanana River from the Johnson River to the Delta River, and northeastern GMU 20D (NE20D), the area north of the Tanana River and east of the Volkmar River. Land in GMU 20D varies from canopy forest and agricultural fields to subalpine terrain. Both subunits have experienced wildfire over the past 20 years, and aerial surveys estimated that moose populations increased steadily until recently (DuBois 2010). However, access into these regions is very different for local hunters. SW20D has an extensive trail network that can be easily accessed via all-terrain vehicles (ATVs) and 4 x 4 trucks, whereas NE20D is difficult to access except for areas along the Tanana River and a few landing strips.

Fig. 2. Map of burns across game management unit 20. The region highlighted with a blue line represents the location of our case study in game management unit 20D.

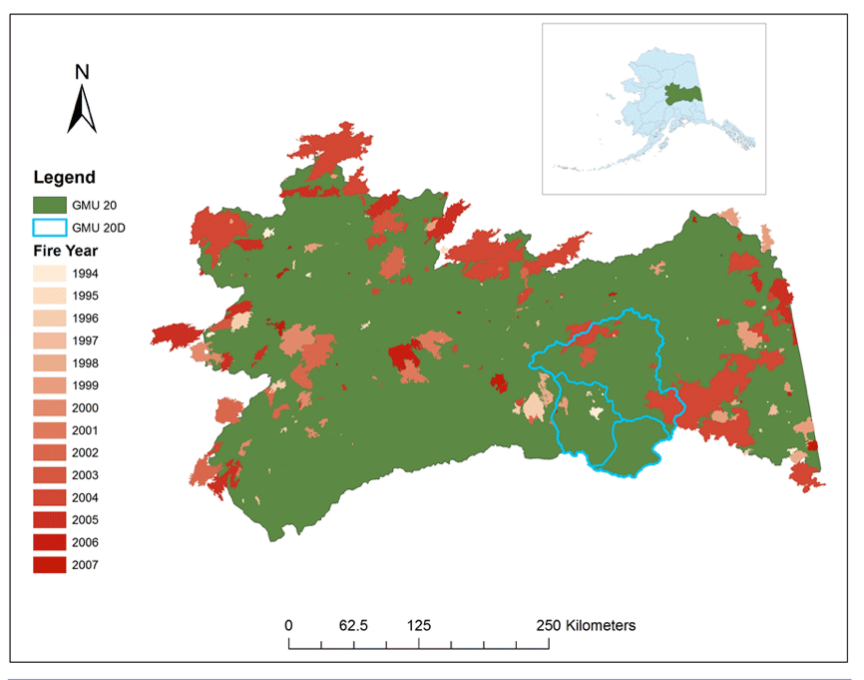

Data collection for moose forage production and removal took place within SW20D in the 19-year-old Hajdukovich Creek burn located 25 miles $(\sim 40 \mathrm{~km})$ east of Delta Junction. In 1994, the fire burned $\sim 8900$ ha of a forest dominated by black spruce stands and a few mixed stands of aspen and spruce (Johnstone and Kasischke 2005). Fire-severity classes were determined by Michalek et al. (2000) and ground-truthed by Shenoy et al. (2011); see Figure 3. Postfire satellite imagery and field-based comparisons of the degree of soil organic matter consumed classified $61 \%$ of the burn as low severity, $6 \%$ as medium severity, and $33 \%$ as high severity.

\section{Ecological components}

We measured forage production and removal using 20 preestablished sites (Johnstone and Kasischke 2005, Lord 2008, Shenoy et al. 2011) stratified by fire severity (Fig. 3). We sampled vegetation during spring 2013 before leaf emergence, March 25 to April 10, in $30 \mathrm{~m}$ diameter circular plots. We randomly located 3 plants from each forage species that were of foraging height for moose (0.5 m to $3.0 \mathrm{~m}$ ): Salix scouleriana, Salix bebbiana, Salix glauca, Salix arbusculoides, Populus tremuloides, and Betula 
neoalaskana. For each plant, we recorded species, height, and dead material (percent by volume), and we estimated the number of current annual growth (CAG) twigs. Calipers were used to record the diameter of the base of CAG for 10 twigs per plant as well as the diameter at the point of browsing (DPB) if twigs were browsed. When necessary, more than 3 plants were sampled until 30 twigs per species or all of the twigs available in the plot were measured. Total stem densities were then estimated for each forage species.

Fig. 3. Fire-severity map of Hajdukovich Creek burn located in southwestern game management unit 20D.

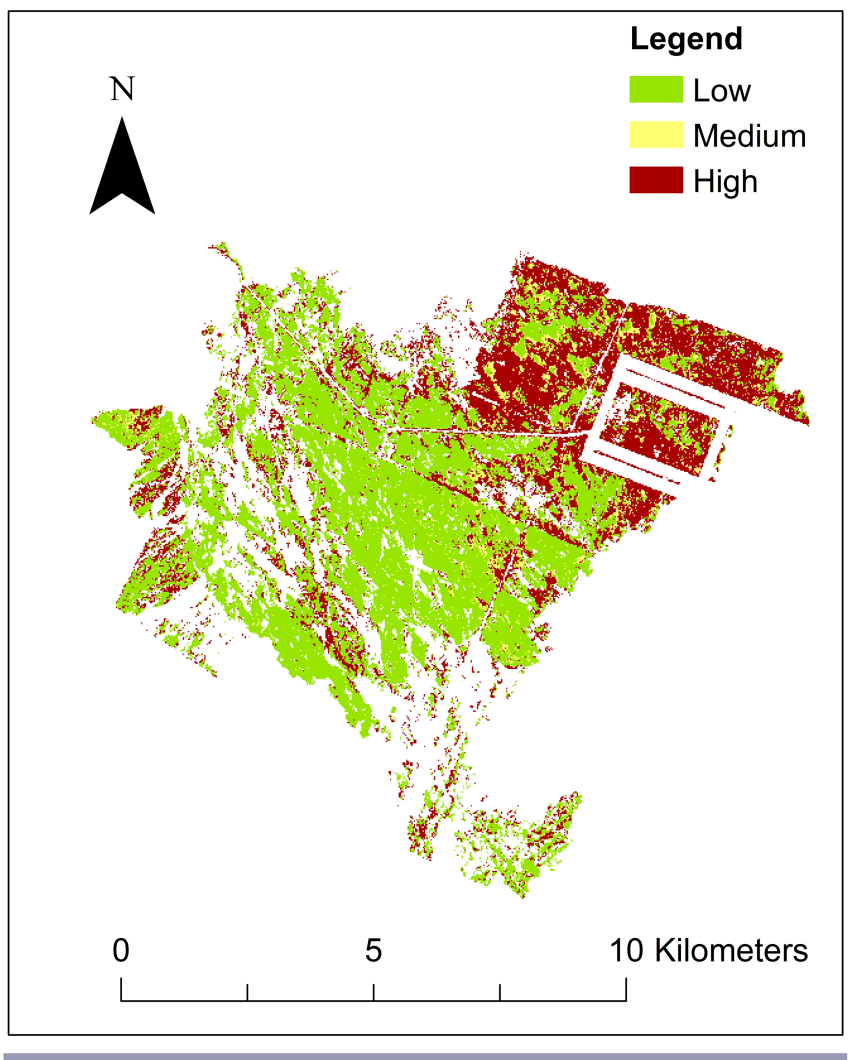

We used regression coefficients established by Paragi et al. (2008) that relate diameter and dry mass of forage species and the number of twigs per plant to estimate production and removal (Telfer 1969). We used diameter of CAG to predict production and diameter of DPB to estimate removal. Proportional offtake of forage biomass was estimated bv the following equation:

$$
\hat{B}_{k}=\sum \frac{M_{j k}}{m_{j k}} \sum \frac{N_{i j k}}{n_{i j k}} \sum \hat{z}_{h i j k}
$$

The estimate of $B k$ is the site estimate of production or removal (g). Twigs are represented by $h$; plants, by $i$; species, by $j$; and the sites, by $k$. $M$ and $m$ are the total and sampled plants in each plot, and $N$ and $n$ are the total and sampled twigs. Individual twig biomass is represented by (Seaton 2002). The formula used for estimating biomass production and removal was as follows:

Forage offtake $=\left(\frac{\Sigma \text { biomass removal from all plants sampled }}{\Sigma \text { CAG biomass produced from all plants sampled }}\right)$
We used a program developed in $\mathrm{R}$ software, version 2.14.1, by the Alaska Department of Fish and Game to read plot counts, twig diameters, diameter-biomass pairs, and dry-weight conversions and to then estimate the diameter-biomass relationships and production and removal $(\mathrm{kg} / \mathrm{ha})$ on the basis of plant, species, plot, and study area (Paragi et al. 2008). Tukey's adjustments for pairwise comparisons were used to test for differences among severity classes. Finally, we compared our results to a previous study (Lord 2008) that utilized the same sites and surveying technique.

\section{Social components}

We used a set of spatial layers to develop an index of hunter accessibility into burns. We used statewide fire maps from the Alaska Interagency Coordination Center (http://fire.ak.blm.gov/ predsvcs/maps.php) for fires that burned between 1994 and 2009, corresponding to the same years in our hunter-harvest database. We also used a statewide travel corridor layer that includes all major highways, roads, trails, and other linear features, e.g., power lines, pipelines, seismic lines, major rivers, and so forth (Fig. 4). In ArcGIS 10.1 (ESRI, Redlands, CA), we used a 2-km buffer to define the areas accessible to hunters via linear features. We chose this buffer distance based on the assumption that hunters would travel within this distance from travel corridors to hunt moose. We intersected this buffered area with fires within GMU 20 to produce a map of burned areas accessible to hunters. We then calculated the accessible area burned for SW20D, NE20D, and the Hajdukovich Creek burn.

Fig. 4. Map of transportation infrastructure including all major highways, roads, trails, and other linear features, e.g., power lines, pipelines, seismic lines, and major rivers, across game management unit 20.

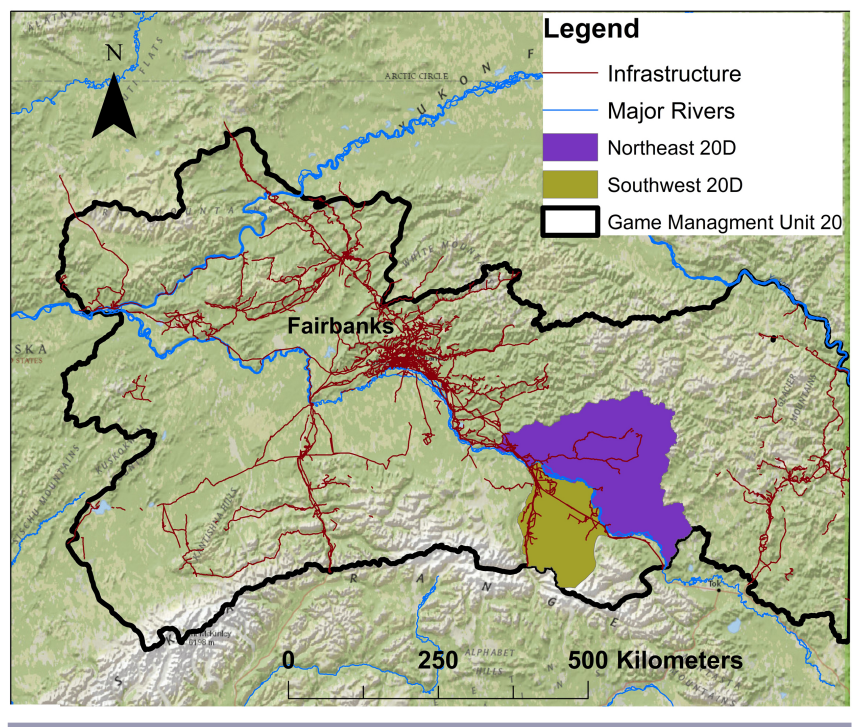

After a moose is harvested, licensed hunters in Alaska must return their harvest tag to Alaska Department of Fish and Game. Annual harvest rates, based on returned harvest tags, provide wildlife managers with information on the relative "success" of hunters within a given area. These tickets include information on the location of hunts, number of permits issued, number of 
hunters, and percent success. We compared local harvest statistics from SW20D and NE20D from 1994 to 2009 (DuBois 2010). We chose this time frame because both subunits experienced wildfires during those decades and moose forage production is typically abundant 10 to 20 years postburn (Gasaway et al. 1989, Loranger et al. 1991). However, hunter access into those subunits is very different.

\section{Management scenarios}

To evaluate the interactions between the social-ecological components of our system, we devised unique management scenarios based on our results. We assume that the management goals are to maintain harvest opportunities commensurate with healthy moose populations. The scenarios represent conditions that managers could encounter following a wildfire event. These scenarios varied in the parameters that differed most strikingly in our field study: forage production, offtake, hunter access, and harvest success.

Each scenario also includes a set of management actions at 2 different timescales postburn: initial prioritization (1-2 years) and continued monitoring (3-15 years). We chose these time periods because postburn management decisions will have to be adaptive as resource conditions change over time. Managers will have to initially prioritize burns to monitor immediately following a fire season, for example, based on burn severity, which controls regeneration patterns (Shenoy et al. 2011). Prioritization will help managers choose which burns have habitat potential and evaluate whether hunters will be able to utilize these areas in the future.

\section{RESULTS}

\section{Ecological components}

Nearly $200 \mathrm{~kg} / \mathrm{ha}$ of forage biomass was produced across all sites within the Hajdukovich Creek burn but varied strikingly depending on the fire severity. High-severity sites produced a mean of $267(\mathrm{SE}=26) \mathrm{kg} / \mathrm{ha}$, medium-severity sites produced 61 $(\mathrm{SE}=5) \mathrm{kg} / \mathrm{ha}$, and low-severity sites produced a mean of 172 $(\mathrm{SE}=16) \mathrm{kg} / \mathrm{ha}$.

The proportion of annual browse production that was consumed by moose (offtake) averaged $23 \%$, but offtake varied as much as 3 -fold among fire severities. Offtake was highest in mediumseverity sites at $33 \%(\mathrm{SE}=7 \%)$, lower in high-severity sites $(27 \%$, $\mathrm{SE}=6 \%)$, and lowest in low-severity sites $(11 \%, \mathrm{SE}=4 \%)$. However, there was a significant difference in forage offtake only between high-severity and low-severity sites $(t=2.2, p=0.05)$.

Whereas the average forage production has increased slightly $(5 \%)$ since 2007 (Lord 2008), the proportional removal across all sites has declined significantly from 33\% in 2007 (Lord 2008) to 23\% in 2013. This decline is especially apparent in high-severity sites where proportional removal has declined by half since 2007 (Lord 2008). These results suggest that moose utilize high-severity sites more than moderate- and low-severity sites. However, as the burn has aged, moose are not utilizing these areas as they have in the past, and high-severity burns may only offer a finite window of forage.

\section{Social components}

GMU 20 contains $15,359 \mathrm{~km}$ of infrastructure available for hunter access (Fig. 4). In our study area, SW20D encompasses $851 \mathrm{~km}$ of infrastructure, whereas NE20D has $680 \mathrm{~km}$ of infrastructure. Between 1994 and 2007, 3 million ha burned within GMU 20.
Of this area, 603,856 ha of burned land is available to hunters via travel corridors. In SW20D, 48,141 ha burned leaving 11,675 ha accessible to hunters. The total land burned in NE20D $(93,885$ ha) was approximately twice the size of burned land in SW20D. However, $<100$ ha of that land is accessible to hunters in NE20D. By contrast, in the Hajdukovich Creek burn ( 8900 ha) 64\% ( 5700 ha) is accessible to hunters.

During 1994-2009, 1577 moose were harvested during the resident general season hunt in SW20D. This resulted in 55\% of the unit $20 \mathrm{D}$ harvest. The average success rate of SW20D was $28 \%$ (SE = $1 \%$ ). During that same period, hunters in NE20D harvested $6 \%$ of the total moose harvest in GMU 20D. However, average success rates in NE20D were 36\% (SE $=3 \%)$ and significantly higher $(t$ $=-2.7, p=0.01)$ than those from SW20D. Just as SW20D supported more than half of the total moose harvested in the unit, the area also supported $52 \%$ of the total number of reported hunters in GMU 20D. By contrast, NE20D represented only 5\% of the total number of hunters in the unit (Table 1). In our study region, SW20D encompasses a greater portion of accessible burned area, supporting both high numbers of hunters and harvested moose. The management implications of these results indicate that regions with more accessible burned areas support higher densities of hunters. However, managers must consider the trade-off between high densities of hunters and competition for moose, which can lower success rates.

\section{Management scenarios}

Managers in Alaska can link the monitoring of both socialecological variables to create management strategies for moose harvest following a wildfire (Table 2). In all of the scenarios, wildlife managers will first need to assess the effects of fire severity on the soil properties and vegetation regeneration that would affect habitat potential for moose. This could involve active collaboration with fire officials or university researchers. During this time, managers will also want to assess whether hunter access exists. If managers find increasing levels of offtake accompanied with signs of habitat degradation attributable to high densities of moose, managers may want to increase levels of harvest by actively providing access into a burn, such as maintaining ATV trails and developing access points, or by liberalizing harvest limits, e.g., longer hunting season or hunting of cows allowed (scenario 3 , Table 2). By contrast, if monitoring indicates high rates of browse production but low levels of offtake in a regenerating burn, managers may need to incorporate additional monitoring efforts such as aerial surveys to monitor predator and moose densities (scenario 2, Table 2). Alternatively, if managers observe low rates of production as well as offtake overtime, they may want to discontinue monitoring the area and refocus management efforts elsewhere or perhaps alter fire management in ways that increase productivity (scenario 1, Table 2). It is important for managers to understand that other variables in this system can affect moose densities and subsequent harvest rates. For example, in our study area the role of predation is likely less important in SW20D compared to NE20D and other more remote areas of Alaska (Boertje et al. 2009). Hunter access is increasing not only moose harvest but also harvest of predators via trapping and hunting. The consequences of these can result in higher moose densities available for hunters. Management scenarios focusing on key drivers in the systems may help elucidate when additional management actions are needed. 
Table 1. The reported number of moose harvested, number of hunters, and percent success adapted from DuBois (2010) in southwestern game management unit 20D and northeastern game management unit 20D.

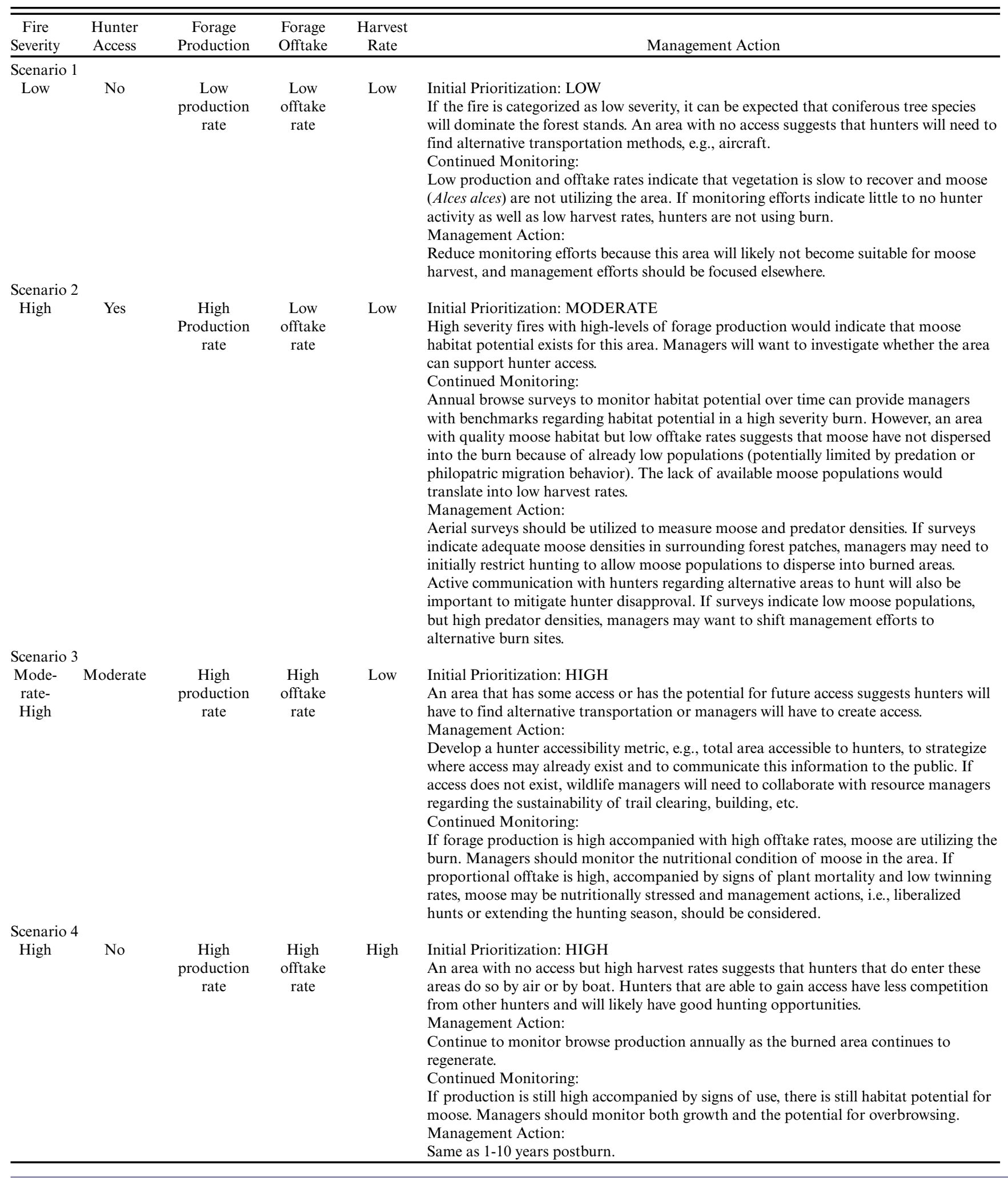


Table 2. Management scenarios following a wildfire in interior Alaska. Each scenario includes a set of management actions at two different timescales postburn: initial prioritization (1-2 years) and continued monitoring (3-15 years). Initial prioritization allows managers to rank burns that have habitat potential for moose (Alces alces) and evaluate whether hunters will be able to utilize these areas in the future. Together these metrics allow managers to prioritize areas as high, moderate, or low for continued management.

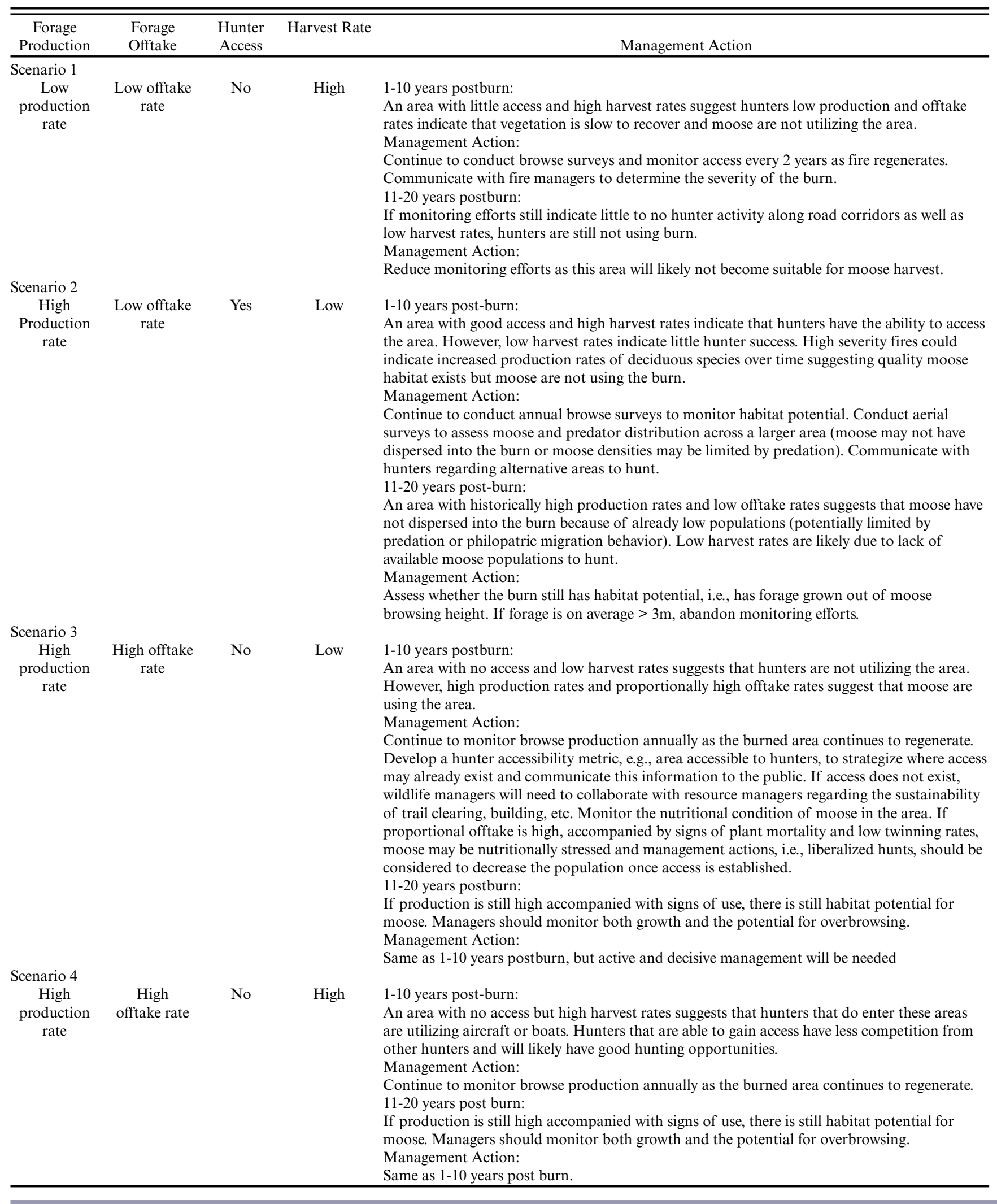


Management scenarios can also be used to forecast changing habitat conditions of wildlife for the human communities that rely on them for ecosystem services. Our results suggest that proportional forage offtake has declined considerably over the past 7 years as the burn in SW20D has aged. Local managers can use these results to forecast changing conditions for both moose and hunters in the region. Management actions will likely vary depending on the timescale of the disturbance (Table 2). It will be important for managers to consider the temporal scale of social-ecological variables on the system when making management decisions. Within this general framework, wildlife managers can use several outlets to respond to a fluctuating moose population following a disturbance including (1) collaboration with fire managers to adapt access where moose may increase, e.g., in high-severity burns; (2) monitoring both moose forage offtake and local harvest rates to track annual use patterns; (3) adapting seasons and bag limits for increasing densities of moose; (4) actively monitoring predator densities and trapping records; and (5) providing ongoing education regarding the relationships between access, moose numbers, and predators so that community members can adapt to these new opportunities and limitations.

\section{DISCUSSION}

Our results clearly show the importance of both ecological and social controls over moose harvest in Alaska. This suggests the need for an availability framework that not only considers the abundance of the game species in question, but also incorporates indices of seasonal wildlife distribution and hunter access when setting management objectives (Brinkman et al. 2013). If managers want to incorporate natural wildfires into management plans, we propose a hunter accessibility metric that accounts for the proximity of regenerating burns to human communities and the availability of travel infrastructure within the area. In addition, monitoring the quality and quantity of roads in popular hunting areas may also be needed when assessing access. Our results suggest that evaluating local harvest tickets in conjunction with access is especially important when accounting for relative success rates. In our study area, the overall harvest success rate was lower in an area with good access (SW20D), indicating that neither moose abundance nor access by itself is sufficient to predict harvest success. The ease of access in this area could actually be affecting the harvest success rates because of competition between hunters. However, how "success" rate is calculated, i.e., proportion of successful harvest tickets returned, may not fully represent the hunting opportunities in an area or whether the hunt was a quality experience. For example, where there are few hunters, success rates are almost always higher, but the number of moose that a given area produces for harvest is low. Thus, wildlife managers may need to develop metrics that incorporate hunter success from the landscape perspective, e.g., number of moose harvested per square kilometer. More research will also be needed on the effects of access on the quality of the hunt, e.g., experience, and effects on wildlife, e.g., shifting distribution attributable to anthropogenic disturbance.

Managers in most situations must choose which variables to monitor to constrain logistical and financial costs. In our system, postfire conditions promote deciduous forage production, i.e., a slow ecological variable, translating into more food for moose. As moose move into burns, the rate of forage removal also increases, i.e., a fast ecological variable, and can strongly influence seasonal harvest opportunities and hunter access, i.e., fast social variables. We recommend that wildlife managers monitor fast variables on a frequent basis, e.g., annually, to adapt and keep their management responsive as resources fluctuate. On the other hand, slower variables, e.g., forage production, may require less monitoring unless the manager is actively attempting to change them through management.

As wildfire characteristics, such as severity, continue to change under a warming climate, managers can expect to see changes to plant species composition, soil-plant interactions, fire return interval, wildlife distribution, and hunting opportunities. A conversion of black spruce stands to aspen following a severe fire can offer opportunities for moose hunters in interior Alaska, but it will require attention to ensuring access into new burned areas. It is clear that managing fire to benefit wildlife will create new and often challenging management decisions. For example, fire suppression decisions will likely hinge on proximity to human infrastructure and may limit future access into areas for subsistence. Collaborative communication between fire and wildlife managers will be very important to the overall success of these strategies. Another key challenge for managers will be prioritizing areas that offer important ecosystem services. This can be especially difficult when operating under finite resources, i.e., limited budgets and staff. Monitoring a few important variables following a fire event, e.g., fire severity and hunter access, can provide information that will aid in the prioritization process. Understanding the slow habitat variables that are driving wildlife population dynamics following a wildfire event will become especially important when setting long-term management goals. However, mangers must also account for fast social-ecological variables to adapt short-term management strategies directly after a wildfire event. We offer a framework that helps navigate these decisions. In a time of rapid change across northern ecosystems, wildlife management must incorporate both adaptive and holistic approaches to managing fluctuating wildlife populations as resource conditions change.

Responses to this article can be read online at: http://www.ecologyandsociety.org/issues/responses. $\mathrm{php} / 7202$

\footnotetext{
Acknowledgments:

Our research was supported by National Science Foundation grant "IGERT: Global-Local Interactions: Resilience and Adaption of Social-Ecological Systems in a Rapidly Changing North" (grant \#0654441). The views expressed are those of the author $(s)$ and do not represent the National Science Foundation. We gratefully acknowledge the Alaska Department of Fish and Game, specifically the Delta Junction Area Office, for providing valuable assistance in the field with data collection. We thank S. DuBois, D. Haggstrom, T. Paragi, T. Seaton, and S. Brainerd for consultation and advice on the project. We thank A. Baltensperger for field assistance and help with analysis of spatial data. Funding to support this research was provided by grants from the University of Alaska Fairbanks Resilience and Adaptation Program.
} 


\section{LITERATURE CITED}

Berg, E. E., J. D. Henry, C. L. Fastie, A. D. De Volder, and S. M. Matsuoka. 2006. Spruce beetle outbreaks on the Kenai Peninsula, Alaska, and Kluane National Park and Reserve, Yukon Territory: relationship to summer temperatures and regional differences in disturbance regimes. Forest Ecology and Management 227:219-232. http://dx.doi.org/10.1016/j.foreco.2006.02.038

Berman, M., and G. Kofinas. 2004. Hunting for models: grounded and rational choice approaches to analyzing climate effects on subsistence hunting in an Arctic community. Ecological Economics 49:31-46. http://dx.doi.org/10.1016/j.ecolecon.2003.12.005

Boertje, R. D., M. A. Keech, D. D. Young, K. A. Kellie, and C. T. Seaton. 2009. Managing for elevated yield of moose in interior Alaska. Journal of Wildlife Management 73:314-327. http://dx. doi.org/10.2193/2007-591

Brinkman, T. J., G. Kofinas, W. D. Hansen, F. S. Chapin III, T. S. Rupp. 2013. A new framework to manage hunting: why we should shift focus from abundance to availability. Wildlife Professional 7:38-43.

DuBois, S. D. 2010. Unit 20D moose. Pages 380-409 in P. Harper, editor. Moose management report of survey and inventory activities 1 July 2007-30 June 2009. Alaska Department of Fish and Game, Juneau, Alaska, USA.

Duffy, P. A., J. E. Walsh, J. M. Graham, D. H. Mann, and T. S. Rupp. 2005. Impacts of large-scale atmospheric-ocean variability on Alaskan fire season severity. Ecological Applications 15:1317-1330. http://dx.doi.org/10.1890/04-0739

Euskirchen, E. S., A. D. McGuire, F. S. Chapin III, and T. S. Rupp. 2010. The changing effects of Alaska's boreal forests on the climate system. Canadian Journal of Forest Research 40:1336-1346. http://dx.doi.org/10.1139/X09-209

Gasaway, W. C., R. D. Boertje, D. V. Grangaard, D. G. Kelleyhouse, R. O. Stephenson, and D. G. Larsen. 1992. The role of predation in limiting moose at low densities in Alaska and Yukon and implications for conservation. Wildlife Monographs 120:1-59.

Gasaway, W. C., S. D. DuBois, R. D. Boertje, D. J. Reed, and D. T. Simpson. 1989. Response of radio-collared moose to a large burn in central Alaska. Canadian Journal of Zoology 67:325-329. http://dx.doi.org/10.1139/z89-047

Johnstone, J. F., and F. S. Chapin III. 2006. Effects of soil burn severity on post-fire tree recruitment in boreal forests. Ecosystems 9:14-31. http://dx.doi.org/10.1007/s10021-004-0042-x

Johnstone, J. F., and E. S. Kasischke. 2005. Stand-level effects of soil burn severity on postfire regeneration in a recently burned black spruce forest. Canadian Journal of Forest Research 35:2151-2163. http://dx.doi.org/10.1139/x05-087

Jorgenson, M. T., V. Romanovsky, J. Harden, Y. Shur, J. O’Donnell, E. A. G. Schuur, M. Kanevskiy, and S. Marchenko. 2010. Resilience and vulnerability of permafrost to climate change. Canadian Journal of Forest Research 40:1219-1236. http:// dx.doi.org/10.1139/X10-060

Kasischke, E. S., D. L. Verbyla, T. S. Rupp, A. D. McGuire, K. A. Murphy, R. Jandt, J. L. Barnes, E. E. Hoy, P. A. Duffy, M.
Calef, and M. R. Turetsky. 2010. Alaska's changing fire regimeimplications for the vulnerability of its boreal forests. Canadian Journal of Forest Research 40:1313-1324. http://dx.doi. org/10.1139/X10-098

Kasischke, E. S., D. Williams, and D. Barry. 2002. Analysis of the patterns of large fires in the boreal forest region of Alaska. International Journal of Wildland Fire 11:131-144. http://dx.doi. org/10.1071/WF02023

Kofinas, G. P., F. S. Chapin III, S. BurnSilver, J. I. Schmidt, N. L. Fresco, K. Kielland, S. Martin, A. Springsteen, and T. S. Rupp. 2010. Resilience of Athabascan subsistence systems to interior Alaska's changing climate. Canadian Journal of Forest Research 40:1347-1359. http://dx.doi.org/10.1139/X10-108

Leonard, J. 2007. Fishing and hunting recruitment and retention in the U.S. from 1990 to 2005: addendum to the 2001 National Survey of Fishing, Hunting, and Wildlife-Associated Recreation. Report 2001-11. U.S. Fish and Wildlife Service, Arlington, Virginia, USA.

Loranger, A. J., T. O. Osborne, T. F. Paragi, J. L. Bodkin, and N. Johnson. 1991. Extent, cause, and timing of moose calf mortality in western interior Alaska. Alces 27:24-30.

Lord, R. E. 2008. Variable fire severity in Alaska's boreal forest: implications for forage production and moose utilization patterns. Thesis. University of Alaska Fairbanks, Fairbanks, Alaska, USA.

Loring, P. A., and S. C. Gerlach. 2009. Food, culture, and human health in Alaska: an integrative health approach to food security. Environmental Science \& Policy 12:466-478. http://dx.doi. org/10.1016/j.envsci.2008.10.006

Markon, C. J., S. F. Trainor, and F. S. Chapin III, editors. 2012. The United States National Climate Assessment-Alaska technical regional report. U.S. Geological Survey Circular 1379. U.S. Geological Survey, Reston, Virginia, USA.

Martin, S., M. Killorin, and S. Colt. 2008. Fuel costs, migration, and community viability. Prepared for the Denali Commission. Institute of Social and Economic Research, Anchorage, Alaska, USA.

Michalek, J. L., N. H. F. French, E. S. Kasischke, R. D. Johnson, and J. E. Colwell. 2000. Using Landsat TM data to estimate carbon release from burned biomass in an Alaskan spruce forest complex. International Journal of Remote Sensing 21:323-338. http://dx.doi.org/10.1080/014311600210858

Nelson, J. L., E. S. Zavaleta, and F. S. Chapin III. 2008. Boreal fire effects on subsistence resources in Alaska and adjacent Canada. Ecosystems 11:156-171. http://dx.doi.org/10.1007/ s10021-007-9114-Z

Paragi, T. F., C. T. Seaton, and K. A. Kellie. 2008. Identifying and evaluating techniques for wildlife habitat management in interior Alaska: moose range assessment. Project 5.10, Alaska Department of Fish and Game, Juneau, Alaska, USA.

Schmidt, J. I., J. M. Ver Hoef, J. A. K. Maier, and R. T. Bowyer. 2005. Catch per unit effort for moose: a new approach using Weibull regression. Journal of Wildlife Management 69:1112-1124. http://dx.doi.org/10.2193/0022-541X(2005)069[1112:CPUEFM]2.0. $\mathrm{CO} ; 2$ 
Schuett, M. A., D. Scott, and J. O’Leary. 2009. Social and demographic trends affecting fish and wildlife management. Pages 18-30 in M. J. Manfredo, J. J. Vaske, P. J. Brown, D. J. Decker, and E. A. Duke, editors. Wildlife and society: the science of human dimensions. Island, Washington, D.C., USA.

Schwartz, C. C., and A. W. Franzman. 1989. Bears, wolves, moose, and forest succession, some management considerations on the Kenai Peninsula, Alaska. Alces 25:1-10.

Scott, C. L., L. A. Brown, G. B. Jennings, and C. J. Utermohle. 2001. Community profile database for Access 2000 (version 3.12). Division of Subsistence, Alaska Department of Fish and Game, Juneau, Alaska, USA.

Seaton, C. T. 2002. Winter foraging ecology of moose in the Tanana Flats and Alaska Range Foothills. Thesis. University of Alaska Fairbanks, Fairbanks, Alaska, USA.

Shenoy, A., J. F. Johnstone, E. S. Kasischke, and K. Kielland. 2011. Persistent effects of fire severity on early successional forests in interior Alaska. Forest Ecology and Management 261:381-390. http://dx.doi.org/10.1016/j.foreco.2010.10.021

Telfer, E. S. 1969. Weight-diameter relationships for 22 woody plant species. Canadian Journal of Botany 47:1851-1855. http:// dx.doi.org/10.1139/b69-271

Titus, K., T. L. Haynes, and T. F. Paragi. 2009. The importance of moose, caribou, deer, and small game in the diets of Alaskans. Pages 137-143 in R. T. Watson, M. Fuller, M. Pokras, and W. G. Hunt, editors. Ingestion of lead from spent ammunition: implications for wildlife and humans. Peregrine Fund, Boise, Idaho, USA. http://dx.doi.org/10.4080/ilsa.2009.0312

Viereck, L. A. 1973. Wildfire in the taiga of Alaska. Quaternary Research 3:465-494. http://dx.doi.org/10.1016/0033-5894(73) 90009-4 